\title{
BINDING INTERACTION BETWEEN POLYCYCLIC AROMATIC COMPOUNDS AND DNA BY FLUORESCENCE DISPLACEMENT METHOD
}

\author{
YIN WeI and Liang-Hong GuO* \\ State Key Laboratory of Environmental Chemistry and Ecotoxicology, Research Center for Eco-environmental Sciences, \\ Chinese Academy of Sciences, P.O. Box 2871, Beijing 100085, China
}

(Received 22 August 2008; Accepted 26 November 2008)

\begin{abstract}
Noncovalent interaction of polycyclic aromatic compounds (PACs) with DNA is the first step in their DNA-damaging actions. The binding interaction of 15 PACs with DNA was investigated by the fluorescence displacement method. A DNA-binding dye with known binding mode was employed as the fluorescence probe. Addition of a DNA-binding PAC into the dye/DNA conjugate sets up a competition between the probe and the PAC for DNA and results in a reduction in fluorescence signal. When thiazole orange, a DNA intercalator, was employed as the probe, the dissociation constants of 1-hydroxypyrene, 1-aminopyrene, and 1-pyrenebutyric acid with calf thymus DNA were determined to be $0.62,1.1$, and $4.7 \mu \mathrm{M}$, respectively. Other PACs, with two to five fused aromatic rings, showed displacement similar to that of 1-pyrenebutyric acid. When the DNA groove-binding agents Hoechst 33258 and 4',6-diamidino-2-phenylindole were used as the probe, none of the PACs exhibited any significant competition with the probe for DNA. The fluorescence data and the viscosity measurement revealed that these PACs interact with DNA predominantly by intercalation instead of the groove-binding mode. The results also suggested that the polar groups on the periphery of the PAC's aromatic ring play a more important role than the number of aromatic rings in determining the binding affinities with DNA. The fluorescence displacement method provides a convenient tool for rapidly investigating the relationship between PAC structure and its DNA-binding properties.
\end{abstract}

Keywords-Polycyclic aromatic compounds DNA binding Fluorescence displacement method Intercalation

\section{INTRODUCTION}

Polycyclic aromatic compounds (PACs) constitute a major class of environmental organic pollutants, which are produced during incomplete combustion of a large variety of organic matter, such as coal, petroleum, garbage, and tobacco. Some PACs have been shown to have mutagenic and carcinogenic effects both in vivo in rodents and in vitro in mammalian (including human) cell lines and have been linked to increased incidences of various types of cancer [1]. Three PACs, benzo[a]anthracene, benzo $[a]$ pyrene, and benzo $[b]$ fluoranthene, were classified as suspected human carcinogens and caused great health concerns. On the other hand, other smaller and larger PACs appear to be less toxic or even nontoxic [2-5]. Obviously, a linkage exists between the PAC structure and its carcinogenic toxicity, although the precise relationship between the two has not been fully revealed.

It is commonly accepted that the critical step in PAC carcinogenesis is the in vivo enzymatic generation of reactive PAC metabolites [6,7]. Three major pathways have been proposed for metabolic activation of PAC - namely, the formation of bay region (three-conjugated ring-system) dihydrodiol epoxide catalyzed by cytochrome P450 enzymes, the generation of radical cation by one-electron oxidation, and the formation of the ortho-quinone pathway by dihydrodiol dehydrogenase [8]. Through studies conducted during the past few decades, the first pathway has been well established and widely accepted as the dominant mechanism of PAC carcinogenesis. In that pathway, three metabolizing enzymes are involved in a stepwise process that ultimately converts PAC to bay region dihydrodiol epoxide, an electrophile capable of binding to DNA.

* To whom correspondence may be addressed (lhguo@rcees.ac.cn).

Published on the Web 12/22/2008.
Further studies concerning the mechanism of interaction of the reactive PAC metabolites with DNA have revealed a process in which the metabolite intercalates rapidly between the base pairs of the DNA helix, followed by covalent binding to deoxyguanosines or deoxyadenosines in DNA [9]. The indication that intercalation is an essential step in DNA adduct formation points to the importance of understanding the mechanism of noncovalent interaction with DNA. Recent work, however, has focused on the identification and characterization of PAC/DNA covalent adducts, especially the metabolites of benzo $[a]$ pyrene [10-16]. A few studies regarding the binding interaction of anthracene, fluorene, and pyrene derivatives to DNA have uncovered the effects of the PAC side chains on their binding modes and affinities [17-23].

Intercalation, groove binding, and electrostatic intercalation are the three major noncovalent binding modes of small molecules to DNA [24-26]. Traditionally, such interactions have been investigated by footprinting and affinity cleavage in combination with nuclear magnetic resonance and x-ray crystallography [27], which provide atomic-level details of DNA/ small-molecule complexes. Without high-resolution structural data, optical spectroscopic methods (including ultraviolet-visible spectrophotometry, fluorescence, circular dichroism, and linear dichroism) as well as hydrodynamic experiments provide indirect evidence to identify the binding modes. Because of its high sensitivity, simplicity, and ease of operation, fluorescence spectroscopy has been widely employed to study the interaction between small molecules and DNA [24,28]. In particular, Tse and Boger [29] have developed a fluorescence displacement assay for the rapid, high-throughput assessment of DNA-binding affinity, sequence selectivity, and binding stoichiometry of drug compounds. In the assay, a fluorescent dye is combined with hairpin deoxyoligonucleotides to generate fluorescence signal. If a test compound binds to DNA, it will 
displace the dye from the nucleotide and reduce the fluorescence. The method was initially developed to test drug compounds but later extended to DNA-binding proteins and enzymes [30,31].

In our present study, the binding interaction of $15 \mathrm{PACs}$ with DNA was investigated by the fluorescence displacement method. The PACs were selected to represent compounds with different numbers of fused aromatic rings and different peripheral functional groups. Our aim was to use the rapid and high-throughput fluorescence displacement method to study both the binding modes and the binding affinities of these PACs with DNA and to shed light on the relationship between PAC structure and its DNA-binding mechanism. It is hoped that the information obtained in the present study may help in understanding the mechanisms of carcinogenesis activity of polycyclic aromatic hydrocarbons (PAHs).

\section{MATERIALS AND METHODS}

\section{Reagents}

Pyrene (purity, $\geq 99.0 \%$ ), benzo[a]pyrene (purity, $\geq 96 \%$ ), benzo[e]pyrene (purity, $\geq 99.0 \%$ ), anthracene (purity, $\geq 99.0 \%$ ), fluoranthene (purity, 99\%), phenanthrene (purity, $98 \%$ ), acenaphthene (purity, $\geq 99.0 \%$ ), phthalazine (purity, 98\%), 9-phenylanthracene (purity, 98\%), 2,3-benzofluorene (purity, 98\%), 1-aminopyrene (purity, $\geq 98.0 \%$ ), 1-pyrenebutyric acid (purity, $\geq 98.0 \%$ ), 1-hydroxypyrene (purity, 98\%), thiazole orange (TO; purity, $\sim 90 \%$ ), double-stranded calf thymus DNA (CT-DNA; 13K base pairs), polydeoxyadenylic acid·polythymidylic acid sodium salt (poly[dA] poly[dT]), and polydeoxyguanylic acid·polydeoxycytidylic acid sodium salt (poly $[\mathrm{dG}] \cdot$ poly $[\mathrm{dC}]$ ) were all purchased from Sigma-Aldrich. Diphenyl (purity, $\geq 98 \%$ ) was obtained from Beijing Chemicals Corporation and fluorene (purity, 98\%) from Shanghai Chemical Reagents Corporation. 4',6-Diamidino-2-phenylindole (DAPI; purity, $>90 \%$ ) was purchased from Roche. Hoechst 33258 (H33258; purity, 99.1\%) was purchased from Merck. All other chemicals and solvents were of analytical grade.

\section{Fluorescence measurement}

Fluorescence emission spectra were recorded on a PerkinElmer LS 55 fluorescence spectrometer at $20^{\circ} \mathrm{C}$ in a right-angle configuration, with a 1-cm light-path quartz cuvette and 10-nm slit width for both excitations and emission. Excitation wavelengths were 504, 345, and $344 \mathrm{~nm}$ for TO, DAPI, and H33258, respectively. The emission spectra were recorded between 510 and $560 \mathrm{~nm}$ for TO and between 400 and 520 $\mathrm{nm}$ for DAPI and H33258. The DNA was dissolved in $50 \mathrm{mM}$ Tris- $\mathrm{HCl}$ buffer ( $\mathrm{pH}$ 7.4). Stock solutions of the tested organic compounds were prepared in methanol and then added into the dye/DNA solution, with the methanol content not exceeding $5 \%$.

\section{Viscosity measurement}

The viscosity change of DNA solutions on addition of PACs and fluorescent dyes was measured with a S-flow viscometer tube (Omnitek) immersed in a thermostat water bath maintained at $30.00^{\circ} \mathrm{C}$. The concentrations of CT-DNA and poly $[\mathrm{dG}] \cdot \operatorname{poly}[\mathrm{dC}]$ were $280 \mu \mathrm{g} / \mathrm{ml}$, whereas the concentration of poly[dA] p poly[dT] was $350 \mu \mathrm{g} / \mathrm{ml}$, all dissolved in $50 \mathrm{mM}$ Tris-HCl buffer ( $\mathrm{pH}$ 7.4). The organic compounds were titrated into the DNA solution from $4 \mathrm{mM}$ stock solutions in methanol. The relative viscosity of DNA $(\eta)$ was calculated from the equation $\eta=\left(t-t_{0}\right) / t_{0}$, where $t$ is the observed flow time of the DNA solution and $t_{0}$ is the flow time of the buffer alone. Data were plotted as $\left(\eta / \eta_{0}\right)^{1 / 3}$, where $\eta_{0}$ is the relative viscosity of the DNA alone and $\eta$ is the relative viscosity of the DNA/ compound mixture versus the compound concentration in the form of compound per base pair [32].

\section{RESULTS AND DISCUSSION}

\section{Binding of fluorescent probes to DNA}

As described above, our strategy was to use a fluorescent DNA binder as a molecular probe to investigate the PAC/DNAbinding interaction in a displacement assay format. For this strategy to work, a few requirements existed for the fluorescent probe. First, its binding mode with DNA should be known and quite specific. Second, fluorescence enhancement of the probe on binding to DNA must be large enough for easy differentiation between the DNA-bound and unbound molecules. Third, the quantum yield of the DNA-bound probe should be high enough for the displacement assay to be conducted at low probe concentrations. This is necessary because most PACs have limited solubility in aqueous solutions and may displace the probe from DNA only when the probe concentration is low.

Among the commonly used fluorescent DNA binders, TO, DAPI and H33258 fulfill the above requirements [33]. Thiazole orange is widely accepted as a DNA intercalator, whereas DAPI and H33258 are minor groove binders [34-36]. To characterize their binding interaction with DNA, the probe was titrated into double-stranded DNA solution at increasing dye to base pair ratios (dbpr) while its fluorescence emission was measured. As illustrated in Figure 1, the fluorescence intensity of TO in $1 \mu \mathrm{g} / \mathrm{ml}$ of CT-DNA increased progressively from a $\mathrm{dbpr}$ of 0 to 0.7 , then reached a plateau at higher ratios. This suggested that the binding stoichiometry is 1.5 DNA base pairs for each TO molecule, which is consistent with the characteristics of DNA intercalators. Using the Scatchard analysis described by Boger et al. [37], the dissociation constant was calculated to be $0.14 \mu \mathrm{M}$. The titration experiment also was carried out in poly[dA] $\operatorname{poly}[\mathrm{dT}]$ and poly[dG] $\operatorname{poly}[\mathrm{dC}] \mathrm{du}-$ plex solutions. From the fluorescence response curve, the binding stoichiometry and dissociation constant were estimated to be 2.3 and $0.05 \mu \mathrm{M}$, respectively, with poly[dA] poly[dT] and 1.4 and $0.18 \mu \mathrm{M}$, respectively, with poly[dG] poly[dC]. It seems that TO binds to adenine-thymine (AT) and guaninecytosine (GC) pair with similar affinity but with a slightly higher preference to AT. Nygren et al. [38] have studied the binding interaction of TO with nucleic acids by ultravioletvisible absorption and obtained an association constant of $10^{5.5}$ for CT-DNA, poly $(\mathrm{dA}-\mathrm{dT})_{2}$, and poly $(\mathrm{dG}-\mathrm{dC})_{2}$. The higheraffinity constant obtained in our fluorescence titration experiment may be attributed to the use of different technique and buffer solutions.

The binding interaction of DAPI and H33258 with DNA also was investigated by fluorescence titration, as shown in Figure 2. In CT-DNA, the titration curves of both DAPI and H33258 were similar to that of TO, in that the fluorescence initially increased with dbpr until a ratio of 0.05 and then leveled off. The binding stoichiometry of DAPI and H33258 with CT-DNA therefore was 20 base pairs for each dye molecule, and the dissociation constants were calculated to be 5 and $3 \mathrm{nM}$ for DAPI and H33258, respectively. At the highest DNA-binding ratios, the emission intensity of H33258 was approximately 1.6 -fold stronger than that of DAPI, reflecting 

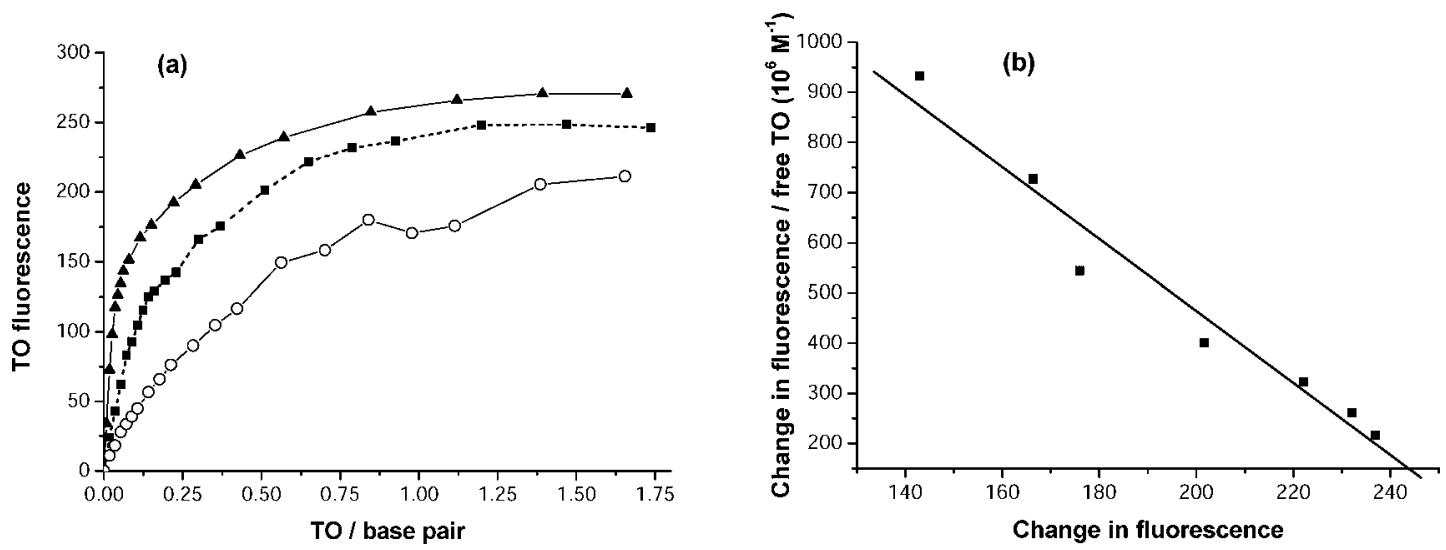

Fig. 1. (a) Fluorescence titration curve of thiazole orange (TO) titrated into $1 \mu \mathrm{g} / \mathrm{ml}$ of calf thymus DNA (CT-DNA; $\mathbf{\square}$ ), polydeoxyadenylic acid polythymidylic acid sodium salt $($ poly $[\mathrm{dA}] \cdot \operatorname{poly}[\mathrm{dT}] ; \mathbf{\Delta})$, and polydeoxyguanylic acid polydeoxycytidylic acid sodium salt (poly[dG]·poly[dC]; O) in $50 \mathrm{mM}$ Tris-HCl buffer (pH 7.4). (b) The corresponding Scatchard plot in CT-DNA.

the higher fluorescence quantum yield of the former dye [33]. In the poly[dA] $\operatorname{poly}[\mathrm{dT}]$ and poly[dG]·poly[dC] duplex, however, the two dyes exhibited fluorescence response remarkably different from that of TO. Essentially no fluorescence was observed for either DAPI or H33258 in the poly $[\mathrm{dG}] \cdot \operatorname{poly}[\mathrm{dC}]$ duplex. In the poly $[\mathrm{dA}] \cdot \operatorname{poly}[\mathrm{dT}]$ duplex, however, the signal increased steadily with the dye concentration until to the highest dbpr investigated (0.17). This suggested that both DAPI and H33258 bind to the AT sequence with higher preference, as expected for DNA minor groove binders. Because of the nonsaturating nature of the titration curve in the range of concentrations studied, binding stoichiometry and affinity constant could not be calculated.

\section{Binding of PACs to DNA}

After the binding interaction of TO, DAPI, and H33258 with DNA was investigated, displacement measurement with PAC was conducted. In the measurement, one of the three dyes was employed as binding probe and mixed with nucleic acid at stoichiometric ratio. A PAC was then titrated into the mixture. If the PAC competes with the probe for the same binding site on the nucleic acid, it will displace the probe from the nucleic acid, resulting in a reduction of the fluorescence signal. From the titration curve, dissociation constant of the PAC with the nucleic acid can be calculated.

Fifteen PACs were tested using TO as an intercalative

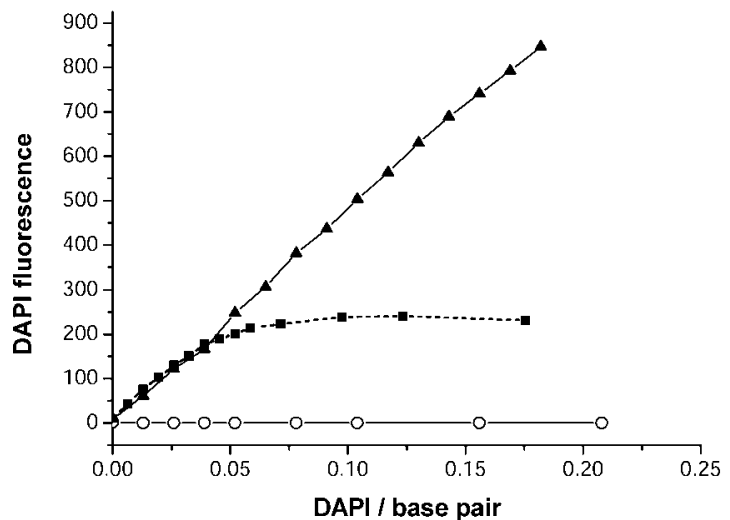

probe. These compounds have different numbers of fused aromatic rings and different peripheral functional groups. Among them, benzo[ $[a]$ pyrene and benzo[e]pyrene are PACs with five fused benzene rings. Pyrene, 1-aminopyrene, 1-hydroxypyrene, 1-pyrenebutyric acid, and 9-phenylanthracene have four benzene rings with different functional side groups. Anthracene, phenanthrene, fluoranthene, and 2,3-benzofluorene are chemicals with three fused aromatic rings. Acenaphthene and fluorene are compounds with two fused benzene rings. In addition, phthalazine is an example of a PAC containing nitrogen atoms in the ring. The concentration of PAC added into the $\mathrm{TO} /$ nucleic acid mixture was increased in a stepwise fashion until the fluorescence was reduced to the background level or the concentration reached its maximum solubility, whichever was less.

The data showed that all the PACs examined displaced TO from the nucleic acids to some extent. Complete loss of fluorescence, however, was obtained only with 1-aminopyrene, 1-hydroxypyrene, and 1-pyrenebutyric acid, because of their high solubilities in aqueous solutions (Figs. 3 and 4). For other PACs, fluorescence signal dropped only by 25 to $35 \%$ before the solubility limit was reached (Supporting Information, Fig. S1; http://dx.doi.org/10.1897/08-394.S1). If the inhibitive concentration at half fluorescence intensity [IC50] is obtained from the displacement measurement, the dissociation constant with the nucleic acid can be calculated according to the formula $K_{\mathrm{d}}$

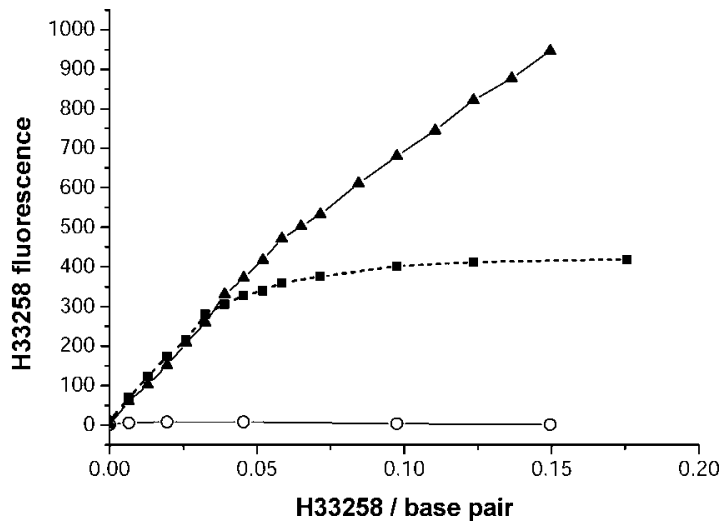

Fig. 2. Fluorescence titration curve of 4',6-diamidino-2-phenylindole (DAPI; left) and Hoechst 33258 (H33258; right) titrated into $1 \mu \mathrm{g} / \mathrm{ml}$ of calf thymus DNA (CT-DNA; $\mathbf{\square}$ ), polydeoxyadenylic acid·polythymidylic acid sodium salt (poly[dA] poly[dT]; $\boldsymbol{\Delta}$ ), and polydeoxyguanylic acid polydeoxycytidylic acid sodium salt (poly[dG] poly[dC]; O) in $50 \mathrm{mM}$ Tris- $\mathrm{HCl}$ buffer (pH 7.4). 

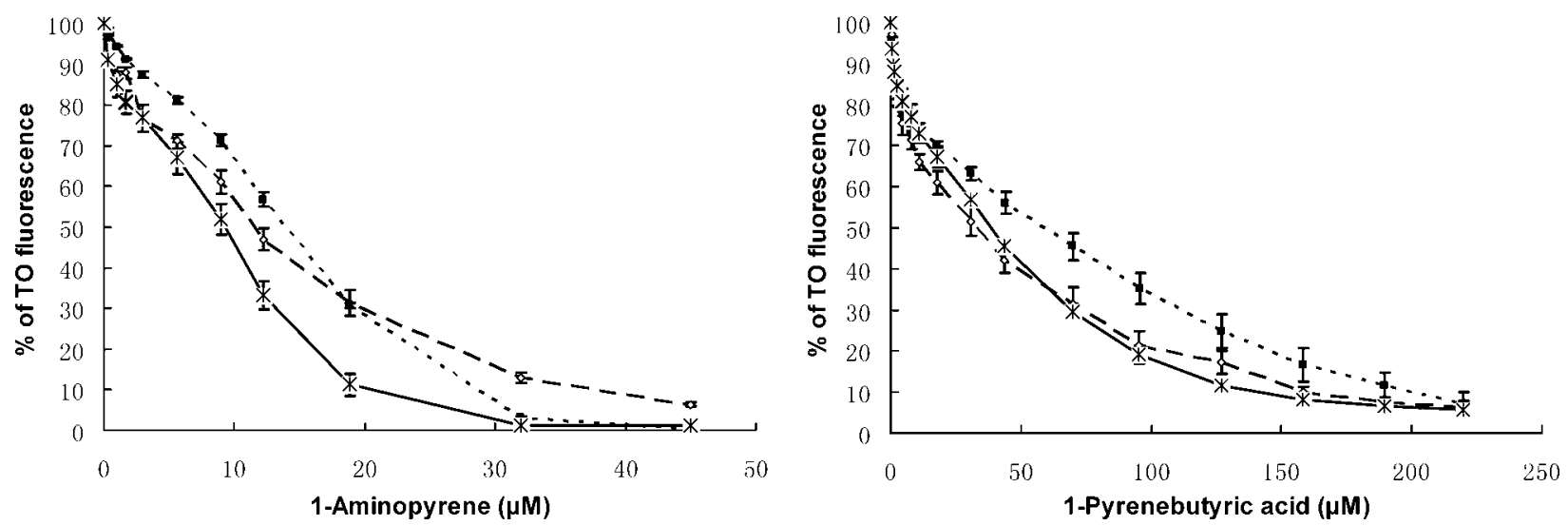

Fig. 3. Fluorescence displacement curves of 1 -aminopyrene and 1-pyrenebutyric acid titrated into $1.0 \mu \mathrm{M}$ thiazole orange (TO) $+1 \mu \mathrm{g} / \mathrm{ml}$ of calf thymus DNA (CT-DNA; *), $0.7 \mu \mathrm{M}$ TO $+1 \mu \mathrm{g} / \mathrm{ml}$ of polydeoxyadenylic acid polythymidylic acid sodium salt (poly[dA] poly[dT]; $\mathbf{\square}$ ), and $2.1 \mu \mathrm{M} \mathrm{TO}+2 \mu \mathrm{g} / \mathrm{ml}$ polydeoxyguanylic acid polydeoxycytidylic acid sodium salt (poly[dG] poly[dC]; $\diamond$ ). Each concentration was repeated three times.

$=[\mathrm{IC} 50] /\left(1+[\right.$ probe $\left.] / K_{\text {probe }}\right)$, where $K_{\mathrm{d}}$ is the dissociation constant, [probe] is the concentration of the fluorescence probe, and $K_{\text {probe }}$ is the dissociation constant of the probe with the nucleic acid [39]. The $K_{\mathrm{d}}$ for 1-hydroxypyrene, 1-aminopyrene, and 1-pyrenebutyric acid with CT-DNA was calculated to be $0.62,1.1$, and $4.7 \mu \mathrm{M}$, respectively. The two pyrene derivatives with peripheral polar groups, 1-aminopyrene and 1-hydroxypyrene, bound to CT-DNA with four- to sevenfold the binding strength of 1-pyrenebutyric acid. It can be postulated that the polar group may provide an additional driving force for the interaction of the compound to DNA.

Although the $K_{\mathrm{d}}$ of the low-solubility PACs with the nucleic acids cannot be calculated from the displacement curves because of the unavailability of an IC50, their affinities can be estimated by comparison with the pyrene derivatives. In Figure 4, the displacement curves for some PACs in CT-DNA were plotted together after normalization of the initial fluorescence intensity. It can be seen that within the solubility range, the displacement curves of the low-solubility PACs were very similar to that of 1-pyrenebutyric acid, suggesting that their dissociation constants should be close to $4.7 \mu \mathrm{M}$.

The TO displacement experiment described above was further performed using two minor-groove binders, H33258 and DAPI, as the fluorescence probe. At the excitation wavelength of the two probes (344 and $345 \mathrm{~nm}$, respectively), some of

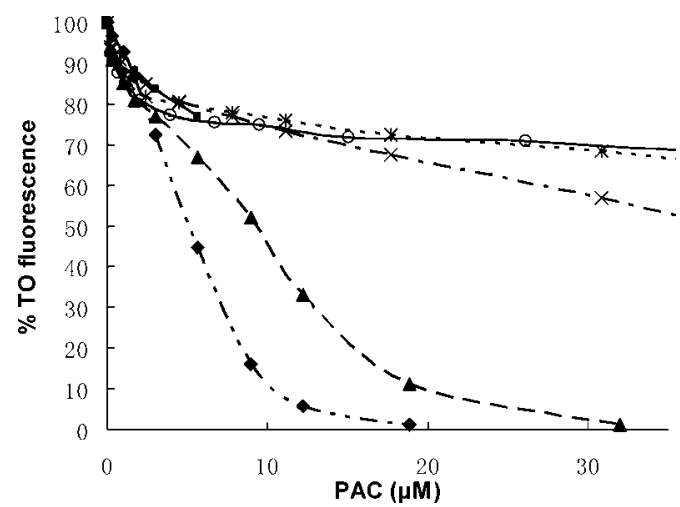

Fig. 4. Fluorescence displacement curves of 9-phenylanthracene $(*)$, diphenyl $(\bigcirc)$, pyrene $(\square), 1$-pyrenebutyric acid $(\times)$, 1-hydroxypyrene $(\checkmark)$, and 1-aminopyrene ( $\mathbf{\Delta})$ titrated into $1.0 \mu \mathrm{M}$ thiazole orange (TO) $+1 \mu \mathrm{g} / \mathrm{ml}$ of calf thymus DNA (CT-DNA). Each concentration was repeated three times. PAC $=$ polycyclic aromatic compounds. the PACs, including 1-aminopyrene, 1-hydroxypyrene, benzo[e]pyrene, and anthracene, emitted higher fluorescence signal at $440 \mathrm{~nm}$ than did the probes at the same concentration. Therefore, these PACs could not be tested in the displacement experiment. For the remaining PACs, benzo $[a]$ pyrene did not reduce the fluorescence of the two DNA-bound probes, indicating no displacement of the minor-groove binders from CTDNA by the compound (Fig. 5a). This also was the case for phthalazine, 2,3-benzofluorene, fluorene, 1-pyrenebutyric acid, fluoranthene, 9-phenylanthracene, acenaphthene, phenanthrene, and pyrene (Supporting Information, Fig. S2; http:// dx.doi.org/10.1897/08-394.S1). Only diphenyl showed a minimal competition with $\mathrm{H} 33258$ and DAPI, because the fluorescence signal was reduced by $10 \%$ after $100 \mu \mathrm{M}$ diphenyl was added into the probe/DNA mixture (Fig. 5b). Therefore, no dissociation constant can be calculated.

Combination of displacement measurements with one intercalative probe, TO, and two minor-groove binders, H33258 and DAPI, provided some insight regarding the binding modes of PACs with DNA. That PACs displaced TO from DNA indicated that these planar aromatic compounds bind to DNA predominantly by intercalation. This fact alone, however, is not sufficient to reach a conclusive statement, because in theory, these compounds can bind to DNA grooves, interfering with the intercalative interaction of TO with DNA and, therefore, exhibit a displacement effect as well. The additional observation that these PACs did not compete with the DNA groove-binding probes made a stronger case for their intercalative binding mode. As shown by scheme S1 in the Supporting Information (http://dx.doi.org/10.1897/08-394.S1), the PACs investigated in the present study have a diverse structure, containing two to five fused aromatic rings. Yet all of them were postulated to bind to DNA by intercalation, and with similar affinities (with the exception of 1-aminopyrene and 1-hydroxypyrene). The data showed that the number of the fused aromatic rings of the tested PACs did not play a crucial role in either their binding modes or their binding affinities with DNA. Horvath et al. [40] employed surface-immobilized DNA and fluorescence polarization technique to detect and quantify a range of polyaromatic chemicals, and those authors found that a minimum structure of two adjacent aromatic rings is necessary for the chemical to bind to the DNA film. This is consistent with our finding that all the PACs with 

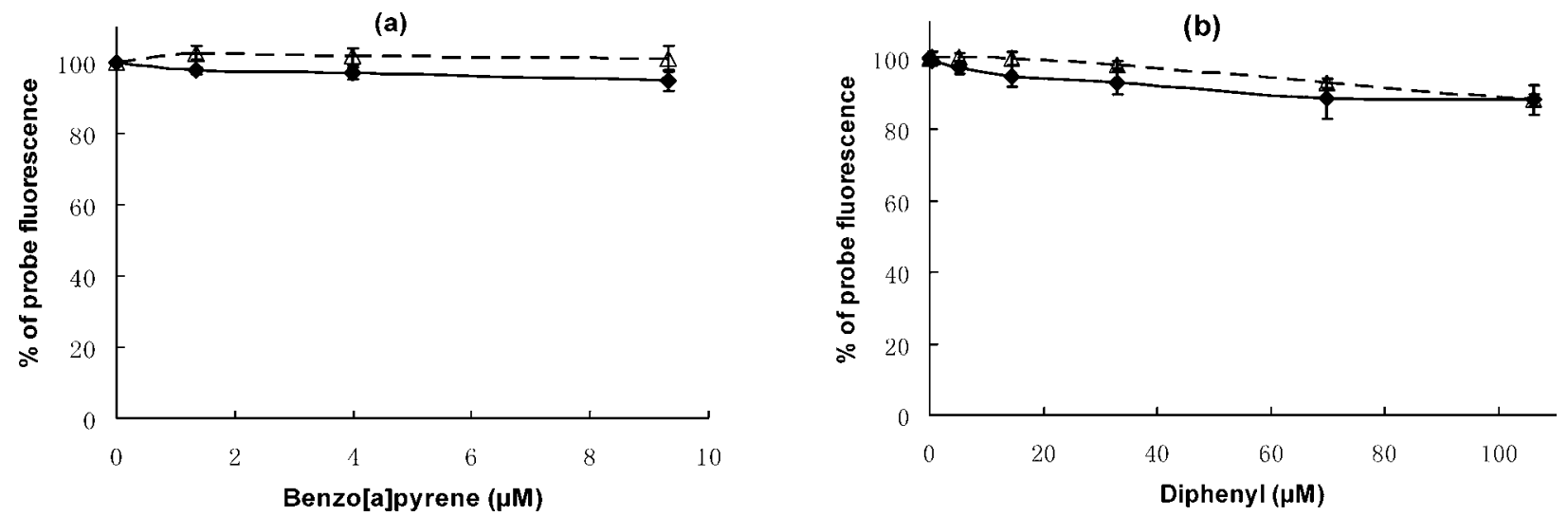

Fig. 5. Fluorescence displacement curves of (a) benzo $[a]$ pyrene and (b) diphenyl titrated into $1 \mu \mathrm{g} / \mathrm{ml}$ of calf thymus DNA (CT-DNA) +0.1 $\mu \mathrm{M}$ 4',6-diamidino-2-phenylindole (DAPI; $\triangle$ ), or $1 \mu \mathrm{g} / \mathrm{ml}$ of CT-DNA $+0.1 \mu \mathrm{M}$ H33258 $(\diamond)$ ). Each concentration was repeated three times.

two or more fused aromatic rings interact with DNA by intercalation.

\section{Viscosity measurement}

To investigate further the binding mode of PACs with DNA, the viscosity of CT-DNA with the addition of tested chemicals and fluorescence probes was measured. Viscosity measurement is a reliable method for identifying the binding mode of chemicals with DNA [24]. In general, DNA intercalators substantially increase the length of DNA, resulting in an increased viscosity. Groove binders, on the opposite, do not lengthen the DNA helix and, therefore, do not increase the viscosity of DNA solutions. Figure 6 showed the results obtained from the viscosity measurement of CT-DNA with increasing amount of TO, H33258, 1-aminopyrene, 1-pyrenebutyric acid, and anthracene. To obtain reliable measurement of the viscosity, a higher concentration of CT-DNA $(280 \mu \mathrm{g} / \mathrm{ml})$ was used compared with that in fluorescence experiment. The tested compound was added into the DNA solution until a clear trend was observed or its solubility limit was reached. As expected, the viscosity increased steadily with addition of the DNA intercalator TO, whereas it did not increase with the minorgroove binder H33258. For the three PACs, the measured viscosity also increased substantially, although not as much as with TO. The results provided additional evidence to support our finding that PACs bind to DNA predominantly by intercalation.

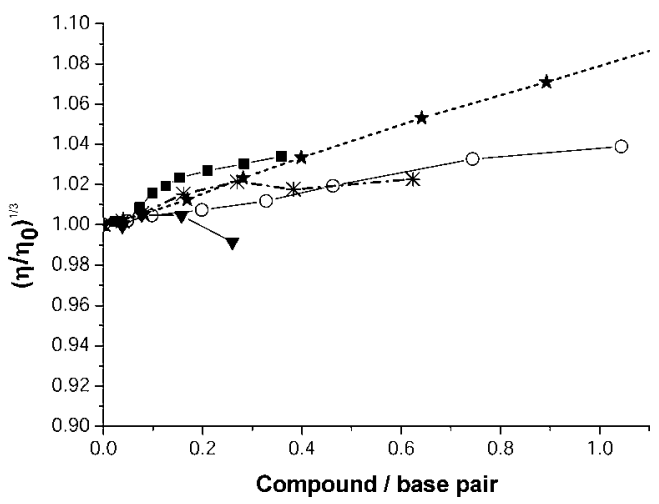

Fig. 6. The relative specific viscosity of $280 \mu \mathrm{g} / \mathrm{ml}$ of calf thymus DNA (CT-DNA) on addition of 1-aminopyrene ( $\square)$, 1-pyrenebutyric acid $(\bigcirc)$, anthracene $(*), H 33258(\boldsymbol{\nabla})$, and thiazole orange $(\mathrm{TO} ; \star)$.

\section{CONCLUSION}

Using the simple and rapid fluorescence displacement measurement, the binding affinities and binding modes of 15 PACs with DNA were investigated. When the DNA-intercalating TO was employed as the fluorescence probe, the dissociation constants of 1-hydroxypyrene, 1-aminopyrene, and 1-pyrenebutyric acid with CT-DNA were determined to be $0.62,1.1$, and $4.7 \mu \mathrm{M}$, respectively. Other PACs, with the number of fused aromatic rings ranging from two to five, showed displacement curves similar to that of 1-pyrenebutyric acid, suggesting approximately the same binding affinities with DNA for these compounds. When the DNA groove-binding agents, H33258 and DAPI, were used as the probe, none of the PACs exhibited any significant competition with the probe for DNA. The fluorescence data and viscosity measurement revealed that these PACs interact with DNA predominantly by intercalation instead of the groove-binding mode. It is postulated that the functional group on the periphery of the PAC's aromatic ring plays a more important role than does the number of aromatic rings in affecting its binding affinity with DNA. As mentioned in the Introduction, in the commonly accepted theory of PAC carcinogenesis, the metabolism of PAC in vivo yields the principal carcinogen, dihydrodiol epoxide, which intercalates rapidly into DNA and forms covalent adduct [6-9]. Most of the PACs investigated in the current work are the parent PAHs, not the metabolites. Although the information obtained from the present study may provide some insight regarding the relationship between chemical structure and DNA-binding properties, it is not very relevant to the understanding of PAH chemical carcinogenesis. Currently, the binding of PAH metabolites with DNA is being investigated in our laboratory. It is hoped that by using the fluorescence displacement method, the relationship between the structure of the PAH metabolite and its DNA-binding properties, such as affinity, binding mode, and DNA sequence selectivity (by using synthetic oligonucleotides with known base sequence) can be investigated conveniently and rapidly.

\section{SUPPORTING INFORMATION}

Fig. S1. Fluorescence displacement curves of 12 polycyclic aromatic compounds titrated into $1.0 \mu \mathrm{M}$ TO $+1 \mu \mathrm{g} / \mathrm{ml}$ of calf thymus DNA (CT-DNA; *), $0.7 \mu \mathrm{M}$ TO $+1 \mu \mathrm{g} / \mathrm{ml}$ of polydeoxyadenylic acid polythymidylic acid sodium salt (poly[dA] poly[dT]; $\square$ ), and $2.1 \mu \mathrm{M}$ TO $+2 \mu \mathrm{g} / \mathrm{ml}$ of polydeoxyguanylic acid-polydeoxycytidylic acid sodium salt 
$($ poly $[\mathrm{dG}] \cdot \operatorname{poly}[\mathrm{dC}] ; \diamond)$. Each concentration was repeated three times.

Fig. S2. Fluorescence displacement curves of nine polycyclic aromatic compounds titrated into $1 \mu \mathrm{g} / \mathrm{ml}$ of calf thymus DNA (CT-DNA) + $0.1 \mu \mathrm{M}$ 4',6-diamidino-2-phenylindole (DAPI; $\triangle$ ), or $1 \mu \mathrm{g} / \mathrm{ml}$ of CT-DNA $+0.1 \mu \mathrm{M}$ Hoechst 33258 $(\mathrm{H} 33258$; $)$. Each concentration was repeated three times.

All found at DOI: 10.1897/08-394.S1 (115 KB PDF).

Acknowledgement-The present study was supported by the Chinese Academy of Sciences (KZCX2-YW-420-1), the National Natural Science Foundation of China (20675087 and 20621703), Scientific Research Foundation for the Returned Overseas Chinese Scholars, Ministry of Education of the People's Republic of China, and Scientific Research Foundation for the Returned Overseas Chinese Scholars, Ministry of Personnel of the People's Republic of China.

\section{REFERENCES}

1. World Health Organization. 1998. Selected nonheterocyclic polycyclic aromatic hydrocarbons. Environmental Health Criteria 202. Geneva, Switzerland.

2. Li D, Wang M, Dhingra K, Hittelman WN. 1996. Aromatic DNA adducts in adjacent tissues of breast cancer patients: Clues to breast cancer etiology. Cancer Res 56:287-293.

3. National Research Council. 1999. Hormonally Active Agents in the Environment. National Academy Press, Washington, DC.

4. U.S. Department of Health and Human Services, Public Health Service, Agency for Toxic Substances and Disease Registry. 1995. Toxicological profile for polycyclic aromatic hydrocarbons. Agency for Toxic Substances and Disease Registry, Washington, DC.

5. International Agency for Research on Cancer. 1983. Chemicals, Environmental and Experimental Data. Part 1. Lyon, France.

6. Miller EC, Miller JA. 1981. Searches for ultimate chemical carcinogens and their reactions with cellular macromolecules. Cancer 47:2327-2345.

7. Harvey RG. 1991. Polycyclic Aromatic Hydrocarbons, Chemistry and Carcinogenicity. Cambridge University Press, Cambridge, UK, pp 11-87.

8. Xue W, Warshawsky D. 2005. Metabolic activation of polycyclic and heterocyclic aromatic hydrocarbons and DNA damage: A review. Toxicol Appl Pharm 206:73-93.

9. Harvey RG, Geacintov NE. 1988. Intercalation and binding of carcinogenic hydrocarbon metabolites to nucleic acids. Accounts Chem Res 21:66-73.

10. Boysen G, Hecht SS. 2003. Analysis of DNA and protein adducts of benzo $[a]$ pyrene in human tissues using structure-specific methods. Mutat Res 543:17-30.

11. Pruess-Schwartz D, Baird WM, Yagi H, Jerina DM, Pigott MA, Dipple A. 1987. Stereochemical specificity in the metabolic activation of benzo[c]phenanthrene to metabolites that covalently bind to DNA in rodent embryo cell cultures. Cancer Res 47: 4032-4037.

12. Rodríguez FA, Cai Y, Lin C, Tang Y, Kolbanovskiy A, Amin S, Patel DJ, Broyde S, Geacintov NE. 2007. Exocyclic amino groups of flanking guanines govern sequence-dependent adduct conformations and local structural distortions for minor groove-aligned benzo[ $[a]$ pyrenyl-guanine lesions in a GG mutation hotspot context. Nucleic Acids Res 35:1555-1568.

13. Ruan Q, Liu T, Kolbanovskiy A, Liu Y, Ren J, Skorvaga M, Zou Y, Lader J, Malkani B, Amin S, Houten BV, Geacintov NE. 2007. Sequence context- and temperature-dependent nucleotide excision repair of a benzo[ $a]$ pyrene diol epoxide-guanine DNA adduct catalyzed by thermophilic UVrABC proteins. Biochemistry 46: 7006-7015.

14. Szeliga J, Dipple A. 1998. DNA adduct formation by polycyclic aromatic hydrocarbon dihydrodiol epoxides. Chem Res Toxicol $11: 1-11$.

15. Fountain MA, Krugh TR. 1995. Structural characterization of a (+)-trans-anti-benzo[a]pyrene-DNA adduct using NMR, restrained energy minimization, and molecular dynamics. Biochemistry 34:3152-3161.

16. Ibanez V, Geacintov NE, Gagliano AG, Brandimarte S, Harvey RG. 1980. Physical binding of tetraols derived from 7,8-dihy- droxy-9,10-epoxybenzo $[a]$ pyrene to DNA. J Am Chem Soc 102: 5661-5666.

17. Becker HC, Norden B. 1999. DNA binding mode and sequence specificity of piperazinylcarbonyloxyethyl derivatives of anthracene and pyrene. J Am Chem Soc 121:11947-11952.

18. Becker HC, Norden B. 2000. DNA binding thermodynamics and sequence specificity of chiral piperazinecarbonyloxyalkyl derivatives of anthracene and pyrene. J Am Chem Soc 122:8344-8349.

19. Modukuru NK, Snow KJ, Perrin BS Jr, Thota J, Kumar CV. 2005. Contributions of a long side chain to the binding affinity of an anthracene derivative to DNA. J Phys Chem B 109:11810-11818.

20. Duff MR, Tan WB, Bhambhani A, Perrin BS Jr, Thota J, Rodger A, Kumar CV. 2006. Contributions of hydroxyethyl groups to the DNA binding affinities of anthracene probes. J Phys Chem B 110: 20693-20701.

21. Eckel LM, Krugh TR. 1994. 2-Aminofluorene modified DNA duplex exists in two interchangeable conformations. Nat Struct Mol Biol 1:89-94.

22. O'Handley SF, Sanford DG, Xu R, Lester CC, Hingerty BE, Broyde S, Krugh TR. 1993. Structural characterization of an $\mathrm{N}$-acetyl-2aminofluorene (AAF) modified DNA oligomer by NMR, energy minimization, and molecular dynamics. Biochemistry 32:24812497.

23. Tanious FA, Jenkins TC, Neidle S, Wilson WD. 1992. Substituent position dictates the intercalative DNA-binding mode for anthracene-9,10-dione antitumor drugs. Biochemistry 31:11632-11640.

24. Suh D, Chaires JB. 1995. Criteria for the mode of binding of DNA binding agents. Bioorg Med Chem 3:723-728.

25. Waring MJ. 1981. DNA modification and cancer. Ann Rev Biochem 50:159-192.

26. Liu XD, Diao HY, Nishi N. 2008. Applied chemistry of natural DNA. Chem Soc Rev 37:2745-2757.

27. Dervan PB. 2001. Molecular recognition of DNA by small molecules. Bioorg Med Chem 9:2215-2235.

28. Armitage BA. 2005. Cyanine dye-DNA interactions: Intercalation groove binding, and aggregation. Top Curr Chem 253:55-76.

29. Tse WC, Boger DL. 2004. A fluorescent intercalator displacement assay for establishing DNA binding selectivity and affinity. Acc Chem Res 37:61-69.

30. Ham YW, Tse WC, Boger DL. 2003. High-resolution assessment of protein DNA binding affinity and selectivity utilizing a fluorescent intercalator displacement (FID) assay. Bioorg Med Chem Lett 13:3805-3807.

31. Eggleston AK, Rahim NA, Kowalczykowski SC. 1996. A helicase assay based on the displacement of fluorescent, nucleic acidbinding ligands. Nucleic Acids Res 24:1179-1186.

32. Cohen G, Eisenberg H. 1969. Viscosity and sedimentation study of sonicated DNA-proflavine complexes. Biopolymers 8:45-55.

33. Cosa G, Focsaneanu KS, McLean JR, McNamee JP, Scaiano JC. 2001. Photophysical properties of fluorescent DNA-dyes bound to single- and double-stranded DNA in aqueous buffered solution. Photochem Photobiol 73:585-599.

34. Loontiens FG, Regenfuss P, Zechel A, Dumortier L, Clegg RM. 1990. Binding characteristics of Hoechst 33258 with calf thymus DNA, poly[d(A-T)] and d(CCGGAATTCCGG): Multiple stoichiometries and determination of tight binding with a wide spectrum of site affinities. Biochemistry 29:9029-9039.

35. Eriksson S, Kim SK, Kubista M, Norden B. 1993. Binding of 4',6-diamidino-2-phenylindole (DAPI) to AT regions of DNA: Evidence for an allosteric conformational change. Biochemistry 32:2987-2998.

36. Kim SK, Eriksson S, Kubista M, Norden B. 1993. Interaction of 4',6-diamidino-2-phenylindole (DAPI) with poly $\left[\mathrm{d}(\mathrm{G}-\mathrm{C})_{2}\right]$ and poly $\left[\mathrm{d}(\mathrm{G}-\mathrm{m} 5 \mathrm{C})_{2}\right]$ : Evidence for major groove binding of a DNA probe. J Am Chem Soc 115:3441-3447.

37. Boger DL, Fink BE, Brunette SR, Tse WC, Hedrick MP. 2001 A simple, high-resolution method for establishing DNA binding affinity and sequence selectivity. J Am Chem Soc 123:5878-5891.

38. Nygren J, Svanvik N, Kubista M. 1998. The interactions between the fluorescent dye thiazole orange and DNA. Biopolymers 46: $39-51$.

39. Cheng YC, Prusoff WH. 1973. Relationship between the inhibition constant $\left(K_{\mathrm{I}}\right)$ and the concentration of inhibitor which causes 50 per cent inhibition $\left(\mathrm{I}_{50}\right)$ of an enzymatic reaction. Biochem Pharmacol 22:3099-3108.

40. Horvath JJ, Gueguetchkeri M, Gupta A, Penumatchu D, Weetall HH. 1995. Biosensor and Chemical Sensor Technology. American Chemical Society, Washington, DC, pp 44-60. 